\title{
O GTP BERTRANDIANO TRANSLADADO PARA A REALIDADE DA GEOGRAFIA BRASILEIRA
}

\author{
Messias Modesto dos Passos ${ }^{1}$
}

Resumo: O objetivo maior desse artigo é, a partir dos meus encontros com Georges Bertrand, mostrar possibilidades de se transladar o que este ilustre geógrafo realizou. Atribuímos a BERTRAND (1968) o mérito de - a partir de uma ruptura epistemológica da Geografia francesa -, passar da "descrição monográfica subjetiva" para o modelo teórico geossistêmico com ênfase para as relações sociedadenatureza. A proposta bertrandiana leva em conta três elementos: o sistema de evolução, o estágio atingido em relação ao clímax, o sentido geral da dinâmica (progressiva, regressiva, estabilidade). Esta tipologia se inspira, portanto, na teoria de bioresistasia de $\mathrm{H}$. ERHART. As nossas conclusões estão explícitas na análise de dinâmicas paisagísticas em duas unidades de paisagem: uma na Calha do rio Amazonas e uma na Bacia Hidrográfica do ribeirão Sto. Antônio/Sudoeste do Estado de São Paulo.

Palavras-chave: Georges Bertrand. Geossistema. Paisagem. Meio Ambiente.

\section{BERTRANDIAN GTP TRANSLATED TO THE REALITY OF BRAZILIAN GEOGRAPHY}

Abstract: The main purpose of this article is, based on my meetings with Georges Bertrand, to show possibilities of translating the accomplishments of this illustrious geographer. We attribute to BERTRAND (1968) the merit of - based on an epistemological rupture of French Geography - shifting from the "subjective monographic description" to the geosystemic theoretical model with an emphasis on society-nature relations. The Bertrandian proposal considers three elements: the evolution system, the stage reached in relation to the climax, and the general sense of the dynamics (progressive, regressive, stability). This typology is inspired, therefore, by H. ERHART's theory of biorhexistasy. Our conclusions are explicit in the analysis of landscape dynamics in two landscape units: an in the Amazon River channel and an in the Santo Antônio brook/southwestern State of São Paulo.

Keywords: Georges Bertrand. Geosystem. Landscape. Environment.

\section{GTP BERTRANDIANO TRADUCIDO A LA REALIDAD DE LA GEOGRAFÍA BRASILEÑA}

Resumen: El principal objetivo de este artículo es, a partir de mis encuentros con Georges Bertrand, mostrar posibilidades de traducir lo que logró este ilustre geógrafo. Atribuimos a BERTRAND (1968) el mérito de - desde una ruptura epistemológica de la Geografía francesa - pasar de la "descripción monográfica subjetiva" al modelo teórico geosistémico con énfasis en las relaciones sociedadnaturaleza. La propuesta bertrandiana tiene en cuenta tres elementos: el sistema de evolución, la etapa alcanzada en relación al clímax, el sentido general de la dinámica (progresiva, regresiva, estabilidad). Esta tipología está, por tanto, inspirada en la teoría de los bioresistas de H. ERHART. Nuestras conclusiones son explícitas en el

\footnotetext{
1 Universidade Estadual Paulista, Campus de Presidente Prudente, Presidente Prudente, Brasil, mmpassos86@gmail.com, https://orcid.org/ 0000-0002-0360-7612
} 
análisis de la dinámica del paisaje en dos unidades de paisaje: un en el cauce del río Amazonas y un en el Sto. Antônio / Suroeste del Estado de São Paulo.

Palabras clave: Georges Bertrand. Geosistema. Paisaje. Medio ambiente.

\section{Introdução}

Ao longo do meu curso de graduação e mesmo ao longo do meu Mestrado na USP (1976-1979) não se falava - ou se falava pouco - da obra de Georges Bertrand. Acredito, que o impacto de Georges Bertrand na Geografia Física brasileira teve início com o artigo: Paysage et géographie physique globale: esquisse méthodologique traduzido pela Profa. Olga Cruz e publicado pelo IGEOG-USP.

No desenvolvimento da minha Tese de Doutorado, na USP (1984 a 1988): O Pontal do Paranapanema: um estudo de geografia física global, todo esforço teóricometodológico foi dedicado à compreensão e aplicação do conceito naturalista de Geossistema. Conceito naturalista, cuja dimensão antrópica não estava, ainda, muito clara para todos nós.

$\mathrm{Na}$ verdade, toda uma geração de geógrafos brasileiros desenvolveu suas respectivas teses de doutorado a partir da leitura de dois artigos - o de Sochava e o de Bertrand -, ambos traduzidos para o português e publicado pelo IGEOG-USP.

As melhores tentativas de compreensão do complexo paisagem, a partir do entendimento de sua estrutura, funcionamento e dinâmica deram-se a partir da Ciência da Paisagem na ex-URSS (Landschaftovedenie), tendo em Sochava a figura maiúscula na elaboração do modelo teórico geossistêmico, que se valeu de uma longa e contínua evolução epistemológica da Geografia Física Complexa desenvolvida na ex-URSS ${ }^{2}$.

Atribuímos à BERTRAND (1968) o mérito de - a partir de uma ruptura epistemológica da Geografia francesa -, passar da "descrição monográfica subjetiva" para o modelo teórico geossistêmico com ênfase para as relações sociedadenatureza.

\footnotetext{
2 Le géosystème soviétique a été inventé pour contribuer à la connaissance pratique des terres vierges de Sibérie à l'échelle d'un continent. Si les ressemblances et les emprunts sont nombreux, il diffère fondamentalement du géosystème "cantabrique". D'une part, c'est un concept strictement matérialiste et naturaliste qui ne fait idéologiquement aucune place à la société et à son impact sur la nature (N. Beroutchachvili). D'autre part, il est fondé sur un grand projet de colonisation et s'appuie sur de puissantes méthodes et technologies de terrain hors de notre portée - Extraído de: Texte remanié de la conférence de clôture prononcée en espagnol à l'Université de Cantabria (Santander) à l'occasion du "día de la Geografía" le 18 octobre 2013, p. 16.
} 
De certa forma, estacionamos na "bíblia" bertrandiana ${ }^{3}$ e na pouca clareza da proposta de Sochava. Ou seja, não fizemos o mergulho suficiente e necessário das obras desses dois biogeógrafos e da própria Ciência da Paisagem e, assim, ficou difícil superarmos a análise dicotomizada dentro da própria Geografia Física (Geomorfologia, Climatologia, Biogeografia, Hidrologia...).

Em maio de 2006, entrevistei o Prof. Georges Bertrand, na Université de Toulouse le Mirail. O Bertrand foi muito atencioso e possibilitou um encontro muito rico e prazeroso. Não demorou muito e ele apresentou-me o convite "para irmos aos Pirineus" A este convite eu contra-ataquei: "não, vamos primeiro ao Brasil". Dessa informalidade, nasceu a formalidade, materializada na concessão dos direitos de tradução e publicação de seu mais recente livro: Une Géographie Traversière L'environnement à travers territoires et temporallités e, mais, a vinda de Prof. Bertrand, como Professor Visitante junto ao Programa de Pós-Graduação em Geografia da UNESP - Campus de Presidente Prudente, em duas ocasiões: 2007 e 2011.

Nessa entrevista, fiz referências à vários artigos de Bertrand, alguns com propostas metodológicas claras, como por exemplo, "Pour une étude géographique de la végétation"4, outros, com méritos epistemológicos bem acentuados, como por exemplo, o artigo: "Pas de territoire sans terre"5. E, notadamente, o artigo Paysage et géographie physique globale. Esquisse méthodologique, que é considerado como o "artigo fundador do G. Bertrand". Este artigo foi, certamente o que mais contribuiu para a notoriedade do Bertrand, na França, no Brasil, na Espanha e em outros países da Europa e da América do Sul.

\section{O Geossistema bertrandiano}

Apesar de ser coerente se considerar "Paysage et géographie physique globale. Esquisse méthodologique" como o artigo fundador de Bertrand, é preciso lembrar que Claude e Georges Bertrand começaram suas investigações nos anos

BERTRAND, G. Paysage et géographie physique globale: esquisse méthodologique. R.G.P.S.O, Toulouse, v. 39, p. 249-72, 1968.

${ }^{4}$ BERTRAND, G. (1966): Pour une étude géographique de la végétation. Toulouse: R.G.P.S-O, t. XXXVII, pp. 129-145.

5IN: CLAUDE e G. BERTRAND: Uma Geografia transversal e de travessias: o meio ambiente através dos territórios e das temporalidades. Maringá: Edição do Autor, 2009 - pp. 194-197. Tradução: Messias Modesto dos Passos. 
1950, quando a geografia em muitos países estava perdendo seu caráter integrador e não propunha os métodos adequados para o estudo do meio natural em sua globalidade. Buscando um novo conceito na tentativa de recuperar o papel da geografia no estudo do meio ambiente se inspiram na ecologia norte-americana, na "Landschaftskunde" alemã, na teoria de sistema e de conjuntos, no conceito de geossistema soviético e em alguns conceitos e métodos de análise integrada. Os autores propõem sua própria metodologia de estudo geográfico do meio ambiente que se baseia no conceito de geossistema. Ainda que o termo e alguns de seus elementos principais foram emprestados do modelo naturalista e quantitativo soviético (V.B. Sochava, A.G. Isachenko). Georges Bertrand adapta o conceito de geossistema a uma realidade distinta, a dos países da Europa Ocidental, com paisagens extremamente antropizadas, porém também às limitações dos recursos materiais dos laboratórios franceses, incomparáveis, nos anos 1960-80, com os soviéticos, simplificando e propondo um modelo mais qualitativo e antropizado.

Em 1964-1965, Bertrand definiu o geossistema como uma unidade taxocorológica, dentre outras: geótopo, geofácies, geossistema, região natural, domínio e zona. O geossistema representa um espaço natural dividido em geofácies. Esta definição taxonômica tem sido utilizada por outros autores, tanto em pesquisas fundamentais como em trabalhos de aplicação. Os estudos que estão contidos neste número da Revue Géographique des Pyrenées et du Sud-Ouest e as legendas de suas cartas foram elaboradas de acordo com este conceito. No entanto, num esforço de uniformização conceitual e de simplificação da linguagem, numa reunião no $\mathrm{CIMA}^{6}$, chegou-se à conclusão de uma definição mais lógica, mais próxima da Escola de Tibilisi - Sochava, Isachenko, Beroutchachvili - que faz do geossistema, como o ecossistema, uma abstração e um conceito.

Ou seja, inicialmente Bertrand considerava o geossistema como uma das unidades horizontais do terreno: geossistema, geofacies e geótopo. Mais tarde, ele próprio reconhece que o geossistema é tão somente um modelo e, portanto, uma abstração e, passa a definir as unidades de terreno, de forma hierárquica: geótopo, geofácies e geocomplexo?.

\footnotetext{
${ }^{6}$ CIMA - Centre Interdisciplinaire de recherche sur les milieux naturels et l'aménagement rural (Unité aassociée du CNRS).

7 A l'origine de la méthode nous avons utilisé le terme de géosystème pour désigner à la fois le concept général et une unité spatiale intermédiaire entre le géofaciés et le pays. L'erreur a été répercutée dans tous les travaux jusque dans les années 1970, en particulier dans les applications
} 
Infelizmente, este reparo epistemológico-teórico-metodológico, não foi absorvido pela comunidade geográfica, não só no Brasil, e continuou-se a se trabalhar com o conceito de Geossistema como se o mesmo se aplicasse à uma unidade territorial qualquer. O mais correto seria adotarmos o termo "geocomplexo" para as unidades de terreno e se considerar o Geossistema como um conceito, um modelo.

A teoria geossistêmica de Bertrand tem como premissas a Soil survey e Land survey anglo-saxões; os geossistemas russos; e mesmo as análises integradas do meio natural (antes da invenção do ecossistema), desenvolvidos para nortear as linhas gerais da organização territorial.

O modelo geossistêmico bertrandiano é constituído de três subsistemas: potencial ecológico/abiótico, exploração biológica/biótico e ação antrópica.

Segundo Bertrand, os especialistas em ciências naturais e os ecólogos não viam com bons olhos o cômputo da intervenção humana. E o que Bertrand fez, na verdade, foi inserir o antrópico no modelo russo - este limitado aos dois subsistemas: potencial ecológico e exploração biológica -, ou seja, partir do pressuposto de que a "natureza não é natural", pois, está irremediavelmente impactada pela sociedade. O fato da natureza estar impactada - pela sociedade não cria ao geossistema o compromisso de estudar a sociedade e, sim, o funcionamento do território modificado pela sociedade.

Portanto, o Geossistema é um conceito antrópico, ou seja, não tem o compromisso de explicar a sociedade e, sim, de explicar o funcionamento do território modificado pela sociedade.

\section{O translado da proposta bertrandiana}

Após a conclusão da Tese de Doutorado passei a desenvolver projetos de pesquisas - apoiados pelo CNPq e pela FAPESP - focados nas temáticas amazônicas - as transformações históricas e as dinâmicas atuais da paisagem,

cartographiques (Pérou, Pyrénées) y compris dans les montagnes cantabriques. Cette regrettable confusion a été corrigée à la suite des critiques de chercheurs soviétiques (D. L. Armand, V. B. Sochava et $\mathrm{N}$. Beroutchachvili). Depuis nous réservons le terme de géosystème au concept général et abstrait, détaché de toute unité territoriale concrète. Dans l'échelle temporo-spatiale de référence et la cartographie afférente, le terme de géosystème est remplacé par celui de géocomplexe (géotope, géofaciès, géocomplexe, pays, région...). - Extraído de: Texte remanié de la conférence de clôture prononcée en espagnol à l'Université de Cantabria (Santander) à l'occasion du "día de la Geografía" le 18 octobre 2013, p. 17. 
notadamente no Vale do Guaporé-Jauru/Sudoeste do Mato Grosso e, em seguida, motivado pelo avanço das frentes pioneiras, passei a priorizar estudos de impactos socioambientais motivados pelas dinâmicas territoriais no eixo da BR-163 (de Cuiabá-MT a Santarém/PA). No entanto, dada as dimensões territoriais, cheguei à conclusão de que "o pó colorido da estrada", apenas, não permitiria diagnosticarprognosticar essas dinâmicas.

E, então, tomei a decisão de realizar o Pós-Doutorado (1992-1993) no Laboratoire Costel/Université Rennes 2-França. O projeto desenvolvido no Costel "La télédéction appliquée au suivi de la colonisation agricole au Mato Grosso - Brésil" não poderia ter sido mais pertinente, em relação aos meus objetivos de pesquisador.

Em 1996, defendi a Tese de Livre Docência ${ }^{8}$, na UNESP - campus de Presidente Prudente - cujo título "Teledetecção aplicada ao estudo da paisagem Sudoeste do Mato Grosso" demonstrava a minha passagem de uma abordagem mais naturalista (Geossistema) para uma abordagem mais polissêmica/multidisciplinar (Paisagem).

Embora eu repetisse, tantas vezes, a expressão "a Geografia se faz, primeiramente, com os pés", depois de algumas reflexões passei a concordar com o Bertrand $^{9}$. Ou seja, a Geografia se faz, primeiramente, com os conceitos, as teorias, os métodos e o rigor epistemológico, próprios da Geografia! inegavelmente, o andar pelo terreno, o observar, o vivenciar as realidades sociais, culturais, econômicas, as identidades das populações locais permitem desenvolver uma "epistemologia sobre o terreno".

Esta epistemologia sobre o terreno é que nos leva à compreensão de que o meio ambiente é um sistema de complexidade com diversidade. É essa aprendizagem que nos motiva a passar de um conceito naturalista para, inicialmente, um conceito naturalista com dimensão antrópica e mais a frente para o modelo GTP: Geossistema-Território-Paisagem.

\footnotetext{
8 ."Teledetecção Aplicada ao Estudo da Paisagem. Sudoeste do Mato Grosso" Tese de LivreDocência, Dpto. De Geografia Humana e Regional da FCT-UNESP, Campus de Presidente Prudente, SP-BR. 1996, 361 pp.

${ }^{9}$ Pour en terminer avec les idées toutes faites, parmi les plus ridicules, il faut dénoncer une fois encore cette niaiserie qui assure que "la géographie se fait par les pieds". Une affirmation qui ne serait que risible si elle n'avait pas contribué à présenter la géographie comme une discipline subalterne, sans armature théorique, conceptuelle et méthodologique. - Extraído de: Texte remanié de la conférence de clôture prononcée en espagnol à l'Université de Cantabria (Santander) à l'occasion du "día de la Geografía" le 18 octobre 2013, p. 7.
} 
Acredito que Bertrand também tenha sido muito influenciado por este estado de espírito, por esta epistemologia sobre o terreno. Explico: primeiramente o Bertrand, no desenvolvimento de sua Thèse de Doctorat, elaborada nas Montanhas Cantábricas, era mais um geógrafo físico, impulsionado pela "revolução copernicana" do final dos anos 1960, início dos anos 1970.

Somente mais tarde é que Bertrand vai mergulhar, no que eu chamaria de "alma bertrandiana", no Sidobre ${ }^{10}$. E, progressivamente vai se afastando do conceito unívoco de Geossistema e passa a se dedicar a toda uma proposta, de caráter mais epistemológico do que metodológico, ou seja, a paisagem/ressourcement.

O Geossistema é um problema ambiental clássico/um conceito naturalista amadurecido. Há outra dimensão ambiental: a paisagem. Como as sucessivas sociedades constroem as sucessivas paisagens para morar, trabalhar e sonhar? É um problema social, econômico e, também, da "vida das pessoas"... Passamos do Geossistema para a história da área, da memória das pessoas.

Além do debate em torno das definições se coloca a questão do "retorno" da paisagem. Há muito tempo esquecida, a paisagem tornou-se atualmente uma preocupação tanto ecológica e econômica como cultural, interferindo com as problemáticas do meio ambiente e da gestão do território.

Mas este novo interesse suscita outros problemas e interrogações. Nós somos confrontados com uma multiplicidade de fontes, de interpretações históricas e de lobbies que se interessam no sujeito. A multiplicação de correntes, tendências de "escolas" que se opõem nas ambições e aspirações diferentes dão uma visão confusa da percepção atual da paisagem. A noção de paisagem procede menos da polissemia que da cacofonia (vazia de sentido, frágil, logomarca etc.); se quer ligar a paisagem às formas de interdisciplinaridade atualmente frágeis. É preciso encontrar outra coisa, fora das disciplinas. É preciso reconhecer e favorecer a diversidade das interpretações e das abordagens. Propor uma abordagem "traversière"11, híbrida, susceptível de associar os contrários: natureza e sociedade, subjetivo e objetivo, individual e coletivo, teórico e prático, ciência e cultura, ordinário e extraordinário etc. que permita passar das teorias às tecnologias, do social ao ambiental. Ou seja,

\footnotetext{
10 L'un d'essence essentiellement naturaliste (Géosystème), l'autre plus largement environnementale et culturelle (système GTP). Si le terrain n'est pas la méthode, il y contribue par les questions spécifiques qu'il pose.

11 traversière quer dizer "ne pas s'arrêter"/jamais parar. É uma etapa...
} 
associar a paisagem ao território no sistema GTP (Geosistema/Território/Paisagem) fundado sobre a trilogia Source-Ressource-Ressourcement ${ }^{12}$.

Em maio de 2007, o Professor Bertrand, na qualidade de Professor Visitante, ministrou, no Programa de Pós-Graduação em Geografia da UNESP, campus de Presidente Prudente, o curso "O meio ambiente e o retorno do geográfico - $A$ pesquisa e o ensino da Geografia face à crise ambiental planetária, de modo particular no Brasil". Nessa visita, Bertrand proferiu palestras em outras instituições públicas: UNESP, campus de Rio Claro, Faculdade de Geografia e História da USPSão Paulo, UNB, UEL, UEM e, ainda, participou das "viagens de estudos" ao Pantanal sul-mato-grossense, ao Recôncavo baiano e à Serra do Mar/Litoral norte paulista.

Acrescentam-se, a essa realização: (a) o retorno do Bertrand, à Presidente Prudente, para ministrar novo curso: "O GTP: a pesquisa de um novo paradigma geográfico"; (b) a proposta da criação de uma "Le reseau paysage"; (c) um profícuo intercâmbio entre nós e a adesão do Jean-Paul Métalié, pesquisador do CNRS, além de Claude Bertrand.

No período de 16 a 20 de junho de 2014, participei das filmagens, no Sidobre $^{13}$, sobre a aplicação do GTP, sob a coordenação do Jean-Paul Métalié e da participação direta e efetiva do Georges Bertrand (Figura 1).

Figura 1 - Filmando no Sidobre - Sudoeste da França, para o documentário vídeo: "As travessias de Georges Bertrand"

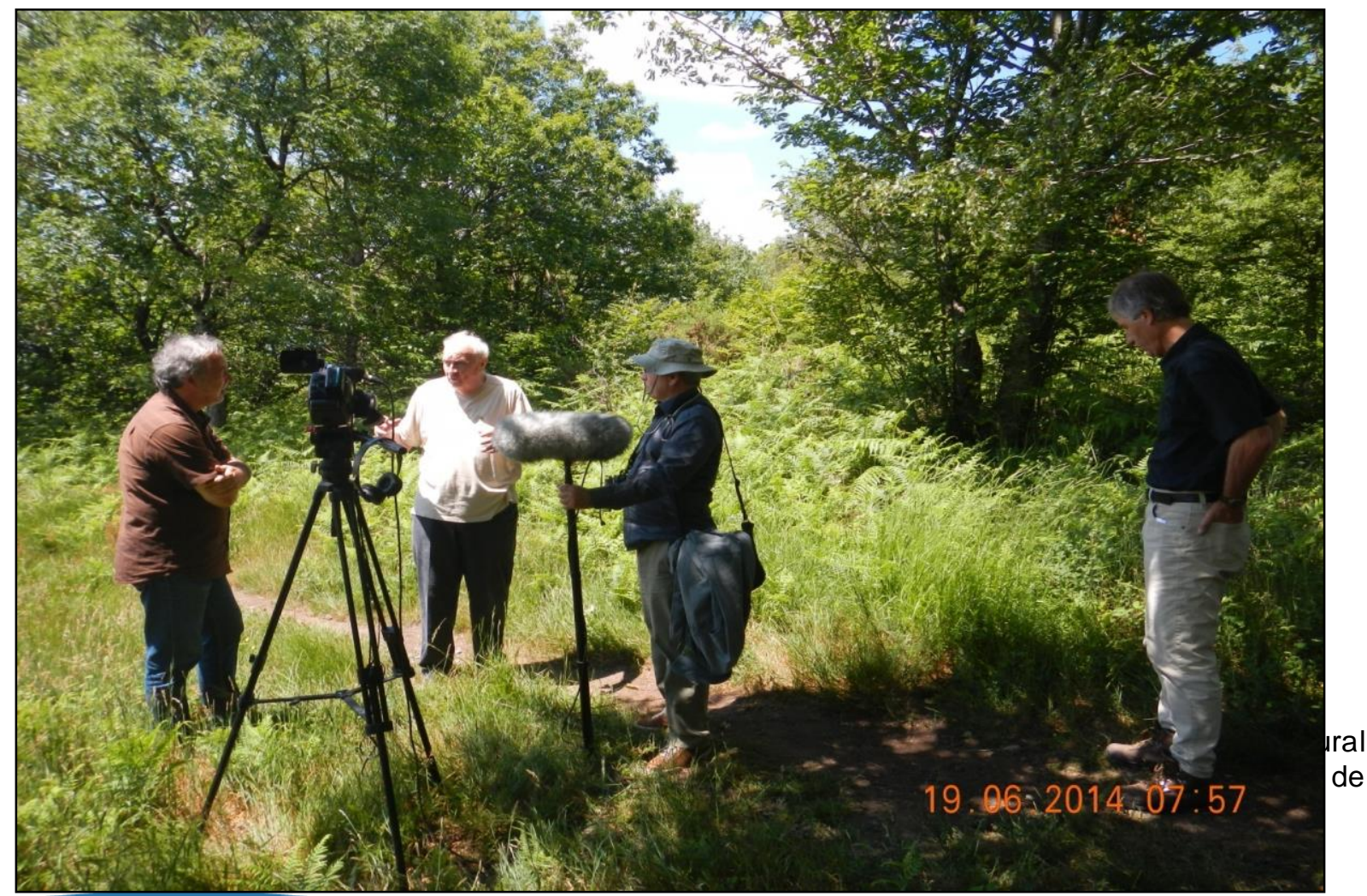


Acredito que com essas linhas, demonstro a aderência do meu caminhar geográfico na busca da construção de uma biogeografia geográfica e, notadamente, de seguir - com pertinência e coerência - a evolução do pensamento desse grande biogeógrafo-geógrafo Georges Bertrand. A quem, deixo aqui os meus mais sinceros agradecimentos por ter me acolhido em parte dos seus caminhos, do seu caminhar.

\section{Novos paradigmas: da síntese ao sistema, do complicado à complexidade}

Se há um contraste de paisagem, há, também, um contraste políticoadministrativo. Para conhecer a Geografia Física é preciso conhecer os problemas sociais, econômicos, administrativos... (Georges Bertrand).

Nesse artigo, vamos avançar um pouco mais nessa coerência de se trabalhar o meio ambiente com a devida pertinência epistemológica, ou seja, um meio ambiente complexo e com diversidade.

A interdisciplinaridade, o globalismo, o ambientalismo e a análise dialética da natureza e da sociedade não puderam se desenvolver senão num ambiente científico dominado pelo espírito de sistema. Era o fim de uma longa tradição de setorização da pesquisa, ao curso da qual, os elementos, isolados de um sistema de referência, conheceram longas derivas. A recentragem em torno dos conceitos de "estrutura" e de "sistema", e do princípio de "auto-organização", relançou a Ecologia em torno do conceito renovado de ecossistema e, a Geografia Física, em torno do conceito de geossistema. Este último é lentamente separado da análise paisagística para dar nascimento a um método naturalista às margens das ciências sociais e das práticas de organização do espaço.

Entre as diferentes abordagens pertinentes à descrição e análise das dinâmicas e organizações espaciais, existem duas grandes orientações que, acredito, devem ser vistas como complementares. Uma, "a análise espacial", consiste em explicitar as grandes regras que estruturam, organizam o espaço. A outra, "a geografia social", aborda os processos de construção territorial pela análise dos comportamentos sociais. A abordagem paisagística se propõe a costurar as relações entre estas duas orientações para mostrar como as diferentes combinações de comportamentos individuais induzem cada uma das construções paisagísticas específicas e, pois, os modelos recorrentes de organização do território. 
Atrás da noção de meio ambiente há um modo de ver, de interpretar e de viver o mundo, ao mesmo tempo global e interativo, que supera e impregna toda análise científica. Ele faz parte da cultura contemporânea da mesma forma que as noções de identidade, de patrimônio, de desenvolvimento, de paisagem. O meio ambiente é muito mais do que um conceito científico.

O fenômeno ambiental nasceu da humanização e da socialização. Ele foi primeiramente cosmogônico e religioso. Para compreendê-lo e dominar seu sentido e seus recursos, a ciência e a técnica o dividiram em frações de saber cada vez mais finas e cada vez mais eficientes, até perder de vista a totalidade e a interatividade.

Só tardiamente, ao longo dos séculos XVIII e XIX, por caminhos diversos e nem sempre convergentes, que certos exploradores e cientistas (sociólogos americanos, naturalistas alemães e anglo-saxônicos, geógrafos alemães e franceses, depois ecologistas) sentiram a necessidade, ao mesmo tempo cultural e científica, de estruturar parcialmente aquilo que havia sido separado e de considerálo como um todo, primeiramente como uma estrutura, em seguida como um sistema funcional. Houve primeiramente uma concepção naturalista do meio ambiente, no início tendo como objeto as plantas e os animais, em seguida a biocenose, enfim, uma concepção ecologicamente mais elaborada, em parte inspirada pelo conceito de ecossistema.

Bertrand chama a atenção para o fato de que a conceitualização unívoca (ex.: ecossistema) que até hoje prevalece permitiu realizar progressos essenciais, porém ainda insuficientes. A ideia consiste em prever várias "entradas" possíveis em um mesmo sistema especulando sobre finalizações possíveis e as hierarquias internas". $E$, então, propõe um sistema com três "entradas" teleológicas ${ }^{14}$ : 1. A fonte ou a "entrada" naturalista: o Geossistema; 2. O recurso ou a "entrada" socioeconômica: o Território; 3. A identidade ou a "entrada" sociocultural: a Paisagem.

A partir de 1990, Bertrand reconhece que não é possível abordar o meio ambiente - complexo e com diversidade -, a partir de um conceito unívoco:

- O ecossistema: um conceito biocêntrico e unívoco (tem como referência maior a biodiversidade);

\footnotetext{
14 Teleológica: um conceito, uma estratégia com finalidade determinada. Por exemplo, para a análise
} naturalista utiliza-se o conceito de Geossistema; para a análise econômica: o conceito de território... 
- O geossistema: um conceito naturalista antropizado e unívoco (tem como referência maior a geodiversidade).

Então, propõe o modelo GTP (Geossistema-Território-Paisagem). Figura 2.

O paradigma GTP, é uma construção de tipo sistêmico destinada a demonstrar a complexidade do meio ambiente geográfico respeitando, tanto quanto possível, a sua diversidade e sua interatividade.

Bertrand (2002) explicita, de forma bastante didática, o sistema metodológico fundado sobre estes três conceitos espaço-temporais:

- O "geossistema" - um conceito naturalista, com dimensão antrópica: representa o espaço-tempo da natureza antropizada. É a "fonte" (source).

- O "território" - um conceito social, com dimensão naturalista: fundado sobre a apropriação e o "limitar/cercar", representa o espaço-tempo das sociedades, aquele da organização política, jurídica, administrativa e aquela da exploração econômica. É o "recurso" (ressource) no tempo curto e instável do mercado.

- A "paisagem" representa o espaço-tempo da cultura, da arte, da estética, do simbólico e do místico. Ela é o ressourcement de tempo longo, patrimonial e identitário. O exemplo da água (fonte e lago) que é considerada "sagrada".

Figura 02 - O sistema GTP, com destaques para os subsistemas Teleológicos, propostos para se estudar o meio ambiente: um sistema complexo e com diversidades.

\section{O SISTEMA GTP}

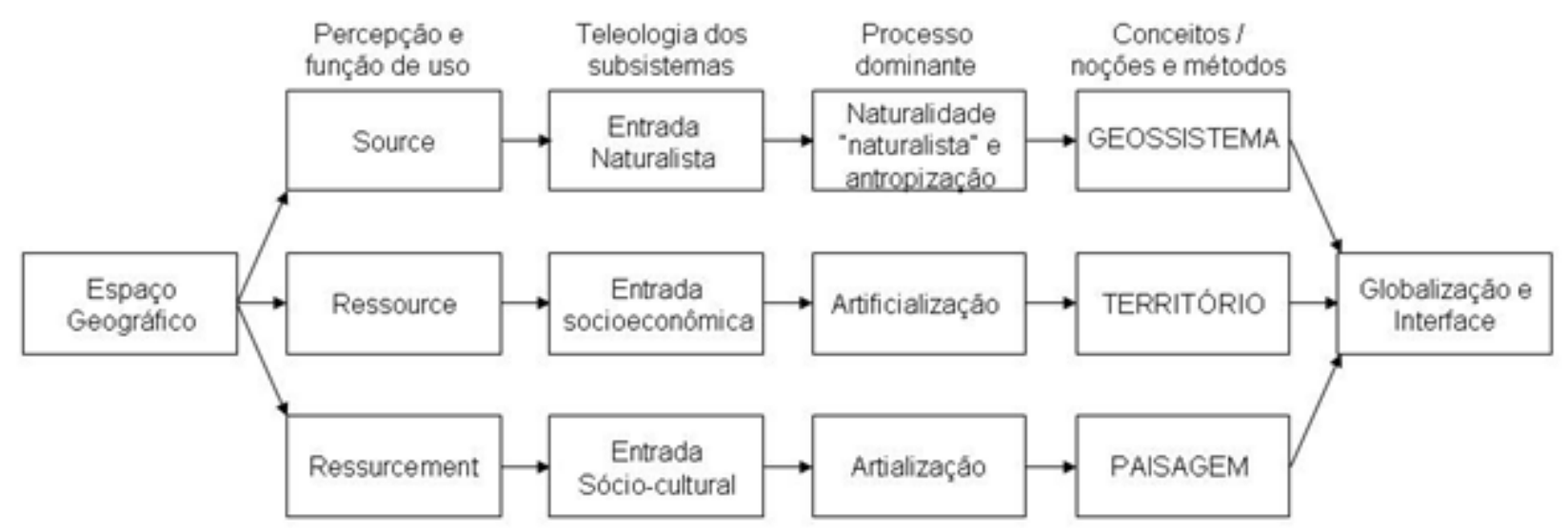

Fonte: Bertrand (2002). 
Um limite decisivo foi superado com a consideração da dimensão social e a exploração da interface natureza-sociedade.

A introdução da dimensão social e cultural vem então reforçar e completar a noção de diversidade que não é apenas de ordem biológica. É bem sabido que o meio ambiente de uns não é o meio ambiente de outros e que muitas incompreensões e conflitos nascem desta situação. Aqui, tocamos exatamente um dos pontos mais sensíveis do desenvolvimento sustentável que a pesquisa sobre ou para o meio ambiente não poderá atingir se não seguir um caminho obrigatório através das culturas e das práticas sociais.

Desde a origem, a pesquisa sobre o meio ambiente está indissoluvelmente ligada à interdisciplinaridade.

Esta é, de fato, sua razão de ser, mas também seu tormento, na medida em que esta situação excepcional é dificilmente admitida pelas disciplinas constituídas e não é claramente reconhecida e bem administrada pelas instituições científicas e administrativas. Os estudos sobre o meio ambiente, sobretudo quando eles se situam na interface entre as ciências da sociedade e as ciências da natureza, são ainda, com muita frequência, uma realização de "invasores de fronteiras", espécie de contrabandistas da pesquisa cuja existência é certamente reconhecida, mas aos quais é permanentemente pedido que justifiquem sua identidade e sua atividade.

A natureza e os fenômenos naturais aí são, certamente, considerados em si mesmos e para si mesmos, mas cada vez mais em uma perspectiva social no amplo sentido, ao mesmo tempo econômico e cultural.

A escolha da entrada paisagística permite associar às pesquisas socioeconômicas concernentes à explicitação dos processos de construção e de recomposição social dos territórios, uma análise da inscrição espacial das relações entre os atores e suas ações e, notadamente, do impacto territorial das políticas sucessivas de desenvolvimento.

A análise das paisagens que aparecem, desaparecem, se estendem ou se fracionam, faz parte das pistas necessárias à elaboração de um diagnóstico territorial sobre o qual se poderiam apoiar as tomadas de decisões tanto ao nível do município como à escala da região.

Nos últimos 20 anos a paisagem tem mudado de estatuto, de finalidade e de conteúdo, participando de forma explícita da cultura, da sensibilidade, do simbólico, 
ou seja, do que se considera de "artialização"15. E mais, a paisagem assume, a cada dia, maior relevância como um dos componentes das políticas de ordenamento ambiental e patrimonial - dos territórios.

A paisagem é o sinal sobre o terreno e o olhar das convulsões ambientais que sacodem o planeta. Trabalhar com a paisagem significa contemplar um paradigma de complexidade e de diversidade que transcende disciplinas e interdisciplinas.

Após uma longa história, se tem dado à paisagem, talvez como último recurso, a missão de interceder para sensibilizar, nos dois sentidos do termo, sobre as questões do território, do meio ambiente, da ordenação e do desenvolvimento.

\section{Qual Geografia?}

A questão não é mais saber se a geografia é a ciência do meio ambiente, mas de considerar a dimensão geográfica do meio ambiente.

geográfico está na mídia, nas políticas de ordenamento territorial e no cotidiano das pessoas. Esse geográfico está explícito na espetacularização do meio ambiente, quer seja através das imagens de catástrofes, de cenários paisagísticos; mas, também, na necessidade de se considerar as potencialidades de determinados territórios em termos de recursos naturais: água, solo, biodiversidade, geodiversidade, fotossíntese etc., nas políticas de Ordenamento do Território.

Em relação ao meio ambiente, a geografia não parece, a priori, uma disciplina mal colocada. Ela não foi, ao menos durante a primeira metade do século XX, uma ciência do meio ambiente ao pé da letra, ocupando uma posição estratégica única entre natureza e sociedade e jogando, em função desse fato, um papel de primeiro

\footnotetext{
15 - L'anthropisation, au sens large d'impact matériel sur la nature, dont l'une des premières manifestations prise scientifiquement en compte a été l'érosion des sols consécutive aux défrichements. Dans notre définition il s'agit de l'ensemble des activités matérielles des sociétés... au moins depuis le néolithique en Europe (agricoles, industrielles, urbaines).

- L'artialisation, au sens large de l'ensemble de la transformation-transfiguration de la nature par toutes les formes de représentation de la pensée et de la sensibilité humaines, des arts, des émotions et des rêves. Une métamorphose de la nature. Cette définition constitue un considérable élargissement par rapport au sens habituel des paysagistes qui limitent l'artialisation à la peinture et aux jardins. ). (Extraído de: C. e G. Bertrand: La Nature-Artefact. Entre Anthropisation et artialisation L'expérience du Système GTP (Géosystème-Territoire-Paysage), P. 11. Géode, Géographie de I'Environnement - UMR CNRS, Université de Toulouse-Le Mirail.
} 
plano no conhecimento do planeta e na valorização dos seus recursos? Esta foi a idade de ouro de uma geografia de síntese, dita regional. A partir dos anos 1950-60, a geografia, enquanto disciplina institucionalizada, deriva para outras problemáticas. Ela passa ao lado da ecologia nascente (1960-1970) e exercita realizações distantes com um meio ambiente atrasado pela longa obediência naturalista. A geografia física, isolada e dividida, esmagada pela preeminência da geomorfologia, não sobreviveu. Atualmente, as reticências subsistem. Elas são mais difíceis de ser levantadas, pois elas procedem, às vezes, da ideologia e da competência científica (por exemplo, no domínio do vivante e das ciências ecológicas).

É inconcebível que a pesquisa sobre o meio ambiente, transdisciplinar por necessidade, possa avançar sem dimensão geográfica afirmada. Qual geografia para qual meio ambiente? Quais convergências epistemológicos e metodológicas entre a ecologia e a geografia? Quais pontos de desentendimento? Quais pontos a superar? Quais avanços comuns?

É preciso reconhecer e favorecer a diversidade das interpretações e das abordagens, propor uma abordagem híbrida e susceptível de associar os contrários: natureza e sociedade, subjetivo e objetivo, individual e coletivo, teórico e prático, ciência e cultura, ordinário e extraordinário etc. É necessário associar a paisagem ao território no sistema GTP.

É preciso construir um sistema a partir dos diferentes elementos. É mais que um simples agregar. É preciso rejeitar a ruptura entre geografia física e geografia humana, aproximar-se da história. É preciso utilizar a geografia para atravessar as outras disciplinas com a condição de traçar um caminho. Como o diz Antonio Machado: 'O caminho, a gente o faz caminhando'. É preciso considerar que desde que a gente fala de paisagem, de meio ambiente, de gestão, de ordenamento ou de território, a gente fala sempre do mesmo objeto.

\section{A geografia física global}

A forma como a Geografia foi construída e a maneira como ela evoluiu, não gerou um conjunto científico coerente. Notadamente na França, onde ela se desenvolveu sob a forte influência de Vidal de La Blache, foi construída para ser uma pedagogia, ou seja, explicar o mundo às novas gerações, à sociedade em geral! A Geografia é uma disciplina universitária, acadêmica e não propriamente o que poderíamos chamar de "ciência". A vantagem da Geografia é que ela é a única disciplina que, no início da sua existência, podia se vangloriar de ser uma "ciência" 
de síntese ao tentar ligar os fatos humanos e naturais. Portanto, era já interdisciplinar e "ciência do meio ambiente" antes mesmo da expressão meio ambiente ganhar a relevância atual.

A partir dos anos 1970 a ecologia, ou melhor, o pensamento e a ideia ecológica vingaram! No entanto, nos dias atuais há uma demanda muito grande de geografia. É o que chamamos de "retorno do geográfico". Não é o retorno da disciplina Geografia; nem a volta do geógrafo. É o retorno da dimensão geográfica das coisas: o espaço, o tempo, o multiescalar, o problema do equilíbrio do meio.

A apreensão da dimensão geográfica só será possível a partir de uma visão do todo, do conjunto, ou seja, avaliar como funciona, nesta condição, a sociedade, os elementos naturais abióticos e bióticos. Portanto, precisarmos aprender uma Geografia "de base": as condições do clima, do solo e da sociedade.

\section{O método GTP - Geossistema - Território - Paisagem: para dominar a complexidade e a diversidade ambiental}

Proposto desde 1990, o sistema GTP, que associa o geossistema-fonte ao território-recurso e à paisagem-identidade ${ }^{16}$ não tem outra razão de ser. É uma tentativa, de ordem geográfica, para matizar, ao mesmo tempo, a globalidade, a diversidade e a interatividade de todo sistema ambiental. Sua função essencial é relançar a pesquisa ambiental sobre bases multidimensionais, no tempo e no espaço, quer seja no quadro de disciplinas ou mesmo em formas de construção da interdisciplinaridade. Sua vocação primeira é favorecer uma reflexão epistemológica e conceitual e, na medida do possível, desencadear proposições metodológicas concretas.

O que conta aqui, antes de tudo, é reaproximar estes três conceitos ou noções para analisar como funciona um meio ambiente geográfico na sua globalidade. Trata-se então, essencialmente, de apreender as interações entre elementos constitutivos diferentes e, muito especialmente, de ver como interagem a paisagem, o território e o geossistema.

\section{O Geossistema - um conceito naturalista com dimensão antrópica}

No início da elaboração do método, G. Bertrand utilizou o termo geossistema para designar, ao mesmo tempo, o conceito geral e uma unidade espacial

\footnotetext{
${ }^{16}$ Géosystème-source - territoire-ressource - paysage-ressourcement.
} 
intermediária entre o geofácies e o domínio. Este erro de Bertrand repercutiu em todos os trabalhos produzidos até os anos de 1970, em particular nas aplicações cartográficas, notadamente na geografia brasileira. Esta lamentável confusão foi corrigida graças às críticas de pesquisadores soviéticos (D.L. Armand, V. B. Sochava e N. Beroutchachvili). A partir dessas críticas, Bertrand reservou o termo geossistema ao conceito geral e abstrato, destacado de toda unidade territorial concreta. Na escala têmporo-espacial de referência e a cartografia correspondente, o termo geossistema é substituído pelo de geocomplexo (geótopo, geofácies, geocomplexo, domínio, região...).

Nesse artigo nós vamos priorizar como devemos definir a tipologia de paisagens e, notadamente, como diagnosticar a dinâmica das unidades de paisagem, em consonância com a análise geossistêmica.

\section{A tipologia das paisagens}

Antes de classificar os geocomplexos, é preciso dar-lhes nomes. Trata-se de definir o mais breve possível combinações ricas, muitas vezes únicas, que escapam às terminologias tradicionais. A solução mais fácil consiste em designar o geocomplexo pela vegetação correspondente que representa muitas vezes a melhor síntese do meio. Como o nome de uma espécie não é suficiente, pode-se reter o da formação vegetal clímax e seu traço ecológico essencial (geocomplexo de mata ciliar, geocomplexo da floresta de vertente úmida...).

Os geofácies se definem facilmente no interior de cada geocomplexo porque eles correspondem sempre a uma combinação característica. Nesta escala, a vegetação fornece os melhores critérios, em particular sob a forma de argumentos fitossociológicos. Aqui, recomenda-se a realização de levantamentos fitossociológicos ${ }^{17}$ e de sua representação cartográfica a partir da "pirâmide de vegetação". A denominação dos geótopos obedece aos mesmos princípios: nascente com bambuzal, veredas com palmeiras, manchas de solo nu...

A escolha caiu numa tipologia dinâmica que classifica os geossistemas em função de sua evolução e que engloba através disso todos os aspectos das paisagens. Ela leva em conta três elementos: o sistema de evolução, o estágio

17 Os procedimentos teóricos-metodológicos para se efetuar os levantamentos fitossociológicos estão muito bem explícitos na publicação: Revista Equador (UFPI), Vol. 5, № 1, (2016). Edição Especial 1, p. 1 - 179. Publicação do livro: O MODELO GTP (Geossistema - Território - Paisagem): Como trabalhar? Home: http://www.ojs.ufpi.br/index.php/equador, págs. 11-125. 
atingido em relação ao clímax, o sentido geral da dinâmica (progressiva, regressiva, estabilidade). Esta tipologia se inspira, portanto, na teoria de bioresistasia de $\mathrm{H}$. ERHART.

\section{Os geossistemas em biostasia}

Trata-se de paisagens em que a atividade geomorfogenética é fraca ou nula. O potencial ecológico é, no caso, mais ou menos estável. O sistema de evolução é dominado pelos agentes e os processos bioquímicos: pedogênese, concorrência entre as espécies vegetais etc. A intervenção antrópica pode provocar uma dinâmica regressiva da vegetação e dos solos, mas ela nunca compromete gravemente o equilíbrio entre o potencial ecológico e a exploração biológica. Esses geossistemas em estado de biostasia classificam-se de acordo com sua maior ou menor estabilidade.

Os geossistemas climácicos, plesioclimácicos ou subclimácicos correspondem a paisagens onde o clímax é mais ou menos bem conservado, por exemplo, uma vertente montanhosa sombreada com cobertura viva contínua e estável, formada por uma floresta heterogênea em solos com horizontes bem definidos. A intervenção humana, de caráter limitado, não compromete o equilíbrio de conjunto do geossistema. No caso de um desmatamento ou mesmo de acidente natural (incêndio), observa-se bem rapidamente uma reconstituição da cobertura vegetal e dos solos; o potencial ecológico não parece modificado.

Os geossistemas paraclimácicos aparecem no decorrer de uma evolução regressiva, geralmente de origem antrópica, logo que se opera um bloqueamento relativamente longo ligado a uma modificação parcial do potencial ecológico ou da exploração biológica. O melhor exemplo é o de áreas desmatadas onde a floresta foi substituída por capoeira.

A base aqui é de origem pedológica. A podzolização interdita todo retorno espontâneo do clímax florestal. A evolução não pode prosseguir senão artificialmente para uma outra forma de clímax (reflorestamento com espécies "pioneiras" após aração profunda).

Os geossistemas degradados com dinâmica progressiva são bem frequentes nas florestas tropicais que, após desmatadas foram "abandonadas". Os territórios rurais cultivados passam ao abandono, vegetação secundária, capoeiras e retorno a 
um estado de floresta-clímax. É o caso de certas áreas declivosas dos territórios rurais da periferia da floresta amazônica.

Os geossistemas degradados com dinâmica regressiva sem modificação importante do potencial ecológico representam as paisagens das áreas de contatos entre o domínio da floresta amazônica e o domínio dos cerrados com economia agropastoril. A vegetação é modificada ou destruída, os solos são transformados pelas práticas culturais e o percurso dos animais. No entanto, o equilíbrio ecológico não é rompido, malgrado um início de ressecamento ecológico. As erosões mecânicas, sempre muito localizadas, guardam um caráter excepcional (por exemplo, ao longo dos caminhos vicinais).

\section{Os geossistemas em resistasia}

A geomorfogênese domina a dinâmica global das paisagens. A erosão, o transporte e a acumulação dos detritos de toda a sorte (húmus, detritos vegetais, horizontes pedológicos, mantos superficiais e fragmentos de rocha in loco) levam a uma mobilidade das vertentes e a uma modificação mais ou menos possante do potencial ecológico. A geomorfogênese contraria a pedogênese e a colonização vegetal. No entanto, é preciso distinguir os 2 níveis de intensidade:

De um lado, os casos de resistasia verdadeira ligados a uma crise geomorfoclimática capaz de modificar o modelado e o relevo. O sistema de evolução das paisagens se reduz então ao sistema de erosão clássico. A destruição da vegetação e do solo pode nesse caso ser total. Cria-se um geossistema inteiramente novo.

Por outro lado, os casos de resistasia limitada à cobertura viva da vertente, isto é, à parte superficial das vertentes: vegetação, restos vegetais, húmus, solos e, às vezes, manto superficial e lençóis freáticos epidérmicos. Esta evolução ainda não interessou suficientemente aos geógrafos e aos biogeógrafos. No entanto, seu interesse é capital do ponto de vista biogeográfico porque ela mobiliza toda a parte biologicamente ativa da vertente. Pode-se qualificar esta erosão de epidérmica para bem distingui-la da erosão verdadeira ou geomorfológica e para evitar as confusões e as discussões inúteis que durante certo tempo puseram em oposição contra e a favor da erosão sob cobertura vegetal. A tipologia dos geossistemas em resistasia deve levar em conta todos esses fatos. 
Os geossistemas com geomorfogênese natural. Nas regiões áridas e semiáridas, assim como na alta montanha, a erosão faz parte do clímax, isto é, ela contribui a limitar naturalmente o desenvolvimento da vegetação e dos solos (vertente montanhosa com talude de detritos móvel, superfície de um glacis de erosão alimentado por escoamento anastomosado).

Os geossistemas regressivos com geomorfogênese ligada à ação antrópica. Já se insistiu longamente sobre este aspecto da dinâmica das paisagens. É preciso encarar 3 casos: primeiro, os geossistemas em resistasia bioclimática cuja geomorfogênese é ativada pelo homem. Em seguida, os geossistemas marginais em mosaico, isto é, com geofácies em resistasia e com geofácies em biostasia, caracterizados por certo desequilíbrio e certa fragilidade natural. Enfim, os geossistemas regressivos e com potencial ecológico degradado que se desenvolvem por intervenção antrópica no seio das paisagens em plena biostasia: certas culturas de plantation, como no avanço da agricultura mecanizada em áreas de cerrados e de floresta amazônica. .

Este esboço tipológico deve ser sumariamente colocado na dupla perspectiva do tempo e do espaço.

No tempo, o problema mais delicado é considerar a parte das heranças. Com efeito, essas não são somente geomorfológicas e pedológicas, mas também florísticas e antrópicas. Seria preciso reconstituir a cadeia histórica dos geossistemas, sobretudo levando em conta a alternância e a duração respectiva das fases de equilíbrio biológico e das fases da atividade geomorfológica.

No espaço, a justaposição dos geossistemas é um fato geral. No entanto, os geossistemas com equilíbrio biológico ocorrem, sobretudo, nas zonas temperadas e tropicais úmidas, assim como em certas regiões de planície. A alta montanha e as diagonais áridas abrigam os geossistemas com maior ou menor atividade geomorfogenética. A exploração antrópica está em vias de perturbar esta distribuição essencialmente bioclimática estendendo os geossistemas em desequilíbrio biológico. Mas a erosão geomorfológica, muitas vezes rápida e espetacular, não se exerce senão em superfícies reduzidas. Em compensação, o verdadeiro perigo do ponto de vista da organização do espaço é a erosão epidérmica que, de forma às vezes insidiosa, arranha a película viva das vertentes em setores extensos sem que se preste a ela uma real atenção. $O$ estudo da 
distribuição espacial dos geossistemas é, pois, um problema de geografia ativa que vem reforçar o interesse da pesquisa cartográfica.

As figuras 3 e 4, são resultados de dois projetos de pesquisa ${ }^{18}$ que desenvolvemos com apoio da Fundação de Amparo à Pesquisa do Estado de São Paulo. A inserção desses croquis, aqui, nesse artigo, se justifica, pois, regra geral, os geógrafos tem abordado o geossistema a partir do modelo clássico: Potencial Ecológico, Exploração Biológica e Ação Antrópica. Esse modelo é o que podemos chamar de "ícone" do modelo geossistêmico bertrandiano. No entanto, não menos importante do que esse, é a análise dinâmica do geocomplexo.

A combinação dos elementos naturais associada à cultura dos seus agentes e sujeitos definem processos que se prestam para diagnosticar-prognosticar as transformações históricas e as dinâmicas atuais da paisagem.

A decomposição do todo espacial em suas partes, ou seja, a subdivisão da área em unidades elementares, tem como fim compreender as "descontinuidades objetivas da paisagem", segundo propôs Bertrand (1968, p. 251).

Partindo dos elementos fornecidos pela pesquisa, é possível uma classificação das unidades componentes da paisagem, em função de uma tipologia dinâmica e da fragilidade dos equilíbrios morfo-pedogenéticos.

Nós vamos demonstrar a coerência dessa análise a partir, repito, de exemplos resultantes dos dois projetos já mencionados, nos seguintes tipos:

\section{a) Exemplo da bacia hidrográfica do ribeirão Santo Antônio/Sudoeste do estado de São Paulo:}

Áreas de vegetação residual em biostasia subclimácica e paraclimácica nessas áreas, o potencial ecológico se mantém praticamente estável e em equilíbrio com a exploração biológica, embora esta se apresente sensivelmente alterada pela ação antrópica, principalmente de sua composição florística e da fauna. A título de exemplificar essa análise inserimos a figura 3, onde a vegetação de mata tropical semidecídua eliminada, foi substituída por espécies vegetais de maior valência

\footnotetext{
18 FAPESP - Processo no 2013-0385-0: Estudo das transformações históricas e da dinâmica atual da paisagem da bacia hidrográfica do ribeirão Santo Antonio na perspectiva do modelo GTP (Geossistema - Território - Paisagem).

FAPESP - Processo no 2017-20224-1: BR-163/Sub-Região da Calha do Amazonas: o papel dos agentes e sujeitos no ordenamento do território e na implementação de políticas públicas.
} 
ecológica (embaúba, taquaras, sapé e o próprio capim colonião, semeado pelos pecuaristas). A madeira de maior valor econômico foi parcialmente retirada de todas as áreas de matas que restaram por efeito da ação antrópica. Embora o potencial ecológico dessa unidade não tenha sido alterado, ele não oferece condições muito favoráveis ao ressurgimento da biota tropical, nos geótopos de onde ela foi eliminada. Certamente, a fase mais favorável - "otimum climaticum" - para o ressurgimento natural da mata certamente tenha passado.

Nas condições biogeográficas atuais - tanto do potencial ecológico, quanto da exploração biológica - se não ocorrerem novas intervenções antrópicas, é possível que essas biotas evoluam para uma dinâmica climácica (plenitude da biostasia), mesmo sofrendo alterações florísticas. O desequilíbrio deu-se no momento em que a ação antrópica se fez presente. Algumas dessas áreas florestadas estão mais bem conservadas (subclimácicas), enquanto outras sofreram uma modificação parcial da exploração biológica (paraclimácica).

Figura 3 - Áreas de vegetação residual em biostasia subclimácica e paraclimácica que, apesar das alterações florísticas, mantém o estado de equilíbrio biostásico: Alta bacia do ribeirão Santo Antônio/sudoeste do estado de São Paulo

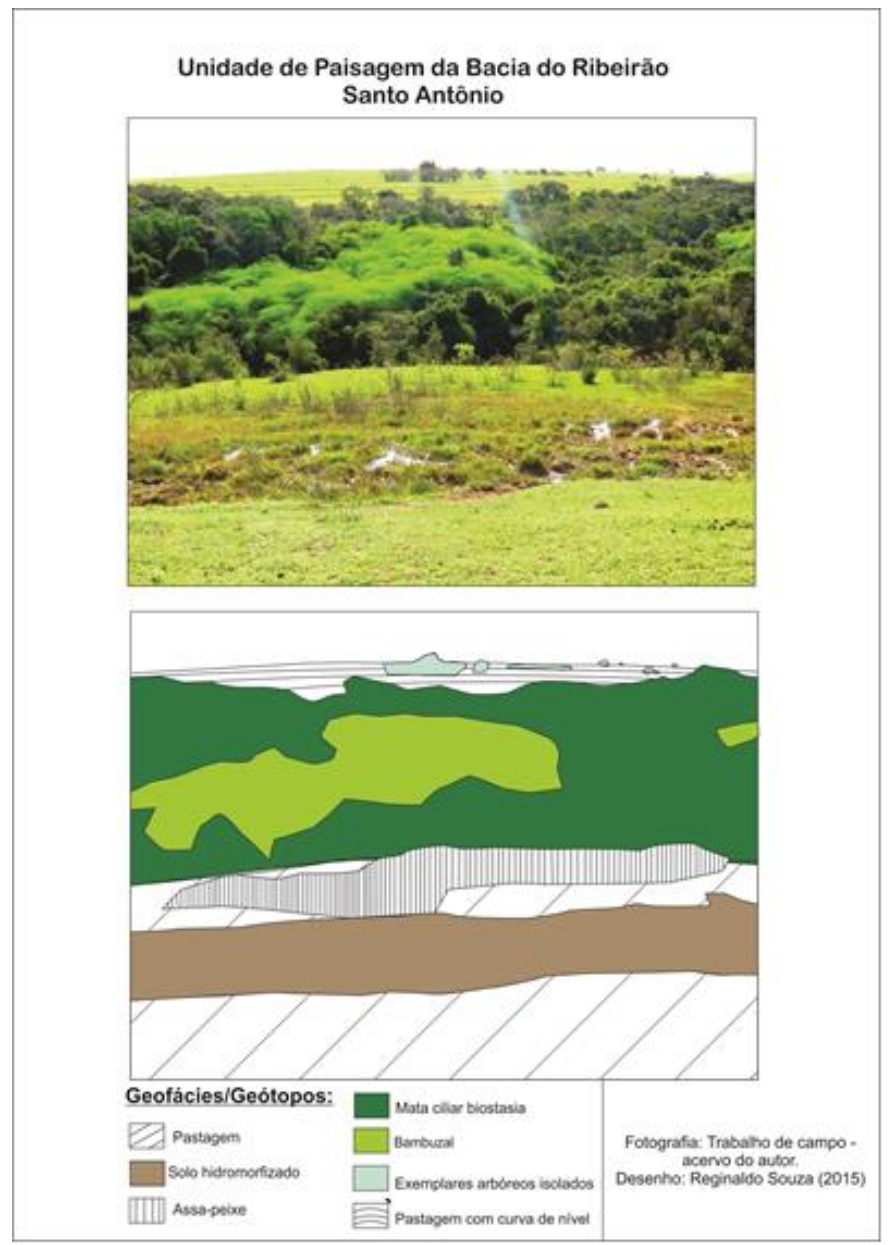




\section{b) Exemplo da calha do rio Amazonas: Santarém, Belterra e Mojuí dos Campos} Área de agricultura mecanizada com dinâmica estável/ em biostasia subclimácica e paraclimácica - área inicialmente sob cobertura de floresta equatorial. O início da ocupação (1950-1970) se deu a partir do assentamento de pequenos agricultores. No entanto, a partir dos anos 1990, a chegada dos sojicultores/agricultura mecanizada, impõe dinâmicas socioculturais e territoriais de grande escala. A nível da dinâmica paisagística, constatamos que, o potencial ecológico se mantém praticamente estável, e em equilíbrio com a exploração biológica, embora esta se apresente sensivelmente alterada pela ação antrópica, principalmente de sua composição florística e da fauna. A título de exemplificar essa unidade, inserimos a figura 4 , onde a vegetação florestal foi, em grande parte eliminada, para implantação de agricultura mecanizada (soja e milho). A madeira de maior valor econômico foi parcialmente retirada de todas as áreas de matas que restaram por efeito da ação antrópica. Embora o potencial ecológico dessa unidade não tenha sido alterado, ele não oferece condições muito favoráveis ao ressurgimento da biota tropical, nos geótopos de onde ela foi eliminada. Certamente, a fase mais favorável - "otimum climaticum" - para o ressurgimento natural da mata talvez tenha passado.

É possível prognosticar que as "ilhas" de florestas "preservadas" no interior das áreas de solo preparado para o plantio, sejam eliminadas, de modo a deixar um espaço contínuo mais apropriado à mecanização, atendendo à cultura dos sojicultores. Algumas dessas áreas florestadas estão mais bem conservadas (subclimácicas), enquanto outras sofreram uma modificação parcial da exploração biológica (paraclimácica). 
Figura 4 - Unidade de paisagem, com vegetação de floreta ilhada por áreas de solo preparado para o cultivo de soja, em biostasia subclimácica e paraclimácica que, apesar das alterações florísticas, mantém o estado de equilíbrio biostásico: propriedade localizada à margem da PA-370, a 10 km da Comunidade de Boa Esperança/Santarém/PA.

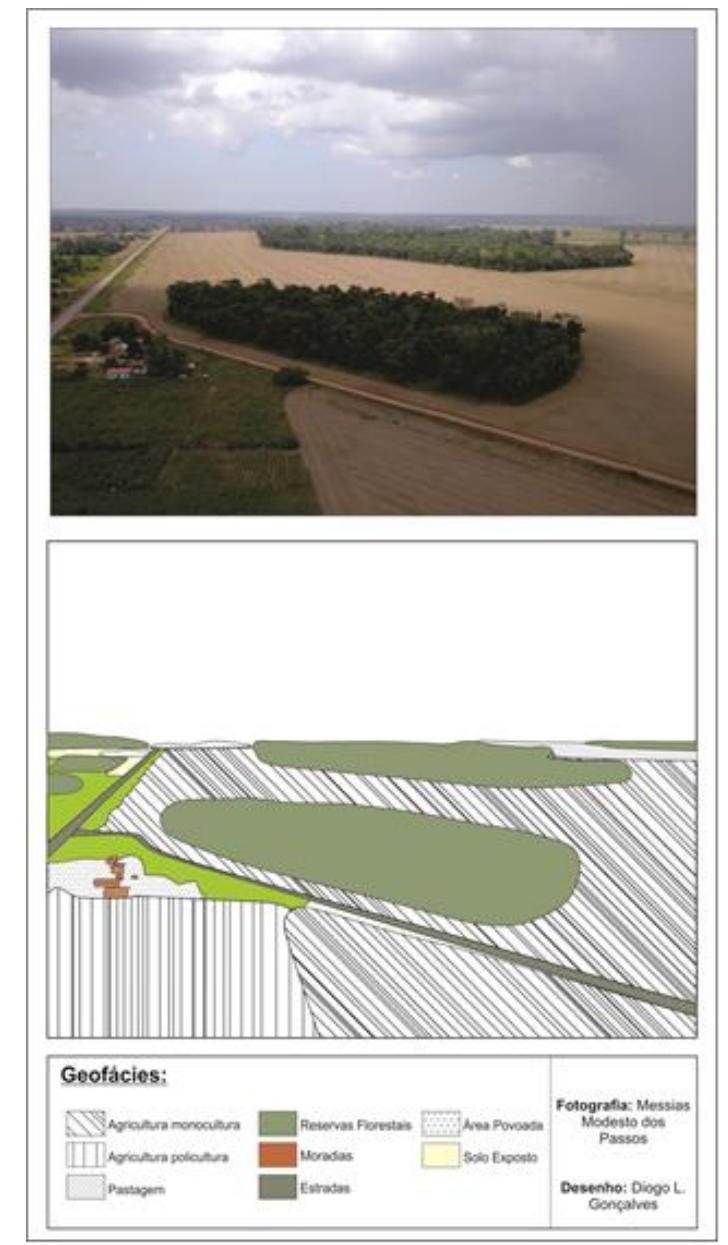

\section{Considerações finais}

O objetivo maior desse artigo é, a partir dos meus encontros com Georges Bertrand, mostrar possibilidades de se transladar o que este ilustre geógrafo francês realizou, a partir de rupturas e de muitas resistências por parte da grande maioria dos geógrafos, seus contemporâneos.

Bertrand é apresentado à geografia brasileira a partir do seu artigo fundador: Géographie Physique Globale: une esquisse métodologique, traduzido pela Olga Cruz e publicado no Caderno de Ciências da Terra, n 13, do IGEOG/USP.

O impacto da obra de Bertrand, inicialmente, foi grande: estávamos em tempos de efervescências, emanadas do que podemos chamar de "revolução copernicana". Era 1968 (final da década de 60, início da década de 70). As 
mudanças (eu ia dizendo: as revoluções) estavam latentes em vários setores: econômico, cultural, científico... As abordagens geográficas, até então centradas na análise setorizada (Geomorfologia, Climatologia, Biogeografia, Hidrografia...) se aproximam das análises integradas, ou seja, ensaiou passar "do complicado para a complexidade".

Foi uma fogueira de pouca lenha: a onda passou... E as disciplinas se trancaram nos seus respectivos ferrolhos. E mais, a hipertrofia da geomorfologia praticamente anulou o conjunto.

No entanto, Beartrand continuou na sua inquietude, na busca de "epistemologia sobre o terreno", na noção de meio ambiente complexo e com diversidades (culturais, econômicas, sociais, institucionais...). E o resultado dessa inquietação foi a elaboração do modelo GTP (Geossistema-Território-Paisagem), ou seja, a constatação de que conceitos unívocos (Ecossistema e Geossistema) por mais relevantes e amadurecidos que estivessem, e estão... não eram/não são suficientes para o estudo do Meio Ambiente. Daí a proposta dessas três entradas: Geossistema (um conceito natural com dimensão antrópica), Território (um conceito social com dimensão naturalista) e Paisagem (o lado sensível da análise ambiental).

A expressão metafórica "a chave e a fechadura", repetidas vezes utilizada por G. Bertrand tem endereço, ou seja, os geógrafos tinham as melhores condições para ocuparem o centro da problemática ambiental: arrolaram os dados, os inventários foram feitos - o relevo, o clima, a vegetação, o solo, a sociedade, a economia etc. $E$ os conceitos de ecossistemas e de geossistemas eram a "chave", isto é, permitiam a análise integrada, a análise do conjunto. Acontece que os geógrafos não acreditaram na possibilidade desses conceitos para "compreender o todo". O conceito de geossistema foi pouco aceito e insuficientemente aplicado porque os geógrafos tinham (e tem) uma visão de "oito ou oitenta", isto é, "já que o geossistema não é capaz de entender literalmente o todo, então qual o sentido de adotá-lo como "procedimento metodológico"? No entanto, ninguém negava a impossibilidade de reunir tudo! Acontece que a essência pode sim constar num modelo conectivo. Sabe-se muito bem que não é possível juntar tudo e que, nem tudo se presta à classificação e pode ser hierarquizado. Ocorrem omissões, "caixas pretas". 
Finalizo, afirmando que nós - a grande maioria dos geógrafos físicos brasileiros - não só simplificamos em demasiado, como mutilamos os modelos bertrandianos.

Passamos do tempo "de que a geografia se fazia com os pés!". Hoje sabemos que a Geografia se faz com os conceitos, as teorias e o rigor epistemológico.

\section{AGRADECIMENTOS}

A Fundação de Amparo à Pesquisa do Estado de São Paulo (FAPESP) pelo apoio no desenvolvimento das pesquisas que motivaram este artigo.

\section{REFERÊNCIAS}

BERTRAND, G. Paysage et géographie physique globale: esquisse méthodologique. R.G.P.S.O, Toulouse, v. 39, p. 249-72, 1968.

BERTRAND, G. . Paisagem e geografia física global: um esboço metodológico. Revista IGEOG/USP, São Paulo: USP, n. 13. Caderno de ciências da terra. Tradução: Olga Cruz. 1972.

BERTRAND, G.; BERTRAND, C. Une géographie traversière - I'environnement travers territoires et temporalités. Paris: éditions Arguments, 2002.

BERTRAND, G.; BERTRAND, C. Uma geografia transversal e de travessias: o meio ambiente através dos territórios e das temporalidades. Tradução: Messias Modesto dos Passos. Maringá: Massoni, 2007.

PASSOS, M. M. O MODELO GTP (Geossistema - Território - Paisagem): Como trabalhar. Revista Equador (UFPI), Vol. 5, № 1, Edição Especial 1, p. 1 - 195. Home: http://www.ojs.ufpi.br/index.php/equador. 2016.

PASSOS, M. M. Biogeografia e Paisagem. Maringá: Massoni, 2 ed. 264 p. 2003.

\section{NOTAS DE AUTOR}

CONTRIBUIÇÃO DE AUTORIA

Messias Modesto dos Passos - Concepção, Elaboração do manuscrito, revisão e aprovação da versão final do trabalho

FINANCIAMENTO

Não se aplica.

CONSENTIMENTO DE USO DE IMAGEM

Não se aplica. 
APROVAÇÃO DE COMITÊ DE ÉTICA EM PESQUISA

Não se aplica.

\section{CONFLITO DE INTERESSES}

Não se aplica.

\section{LICENÇA DE USO}

Este artigo está licenciado sob a Licença Creative Commons CC-BY. Com essa licença você pode compartilhar, adaptar, criar para qualquer fim, desde que atribua a autoria da obra.

\section{HISTÓRICO}

Recebido em: 22-09-2020

Aprovado em: 12-11-2021 